\title{
ANALISIS POSITIONING JASA TRANSPORTASI TRAVEL BANDUNG-JAKARTA PP BERDASARKAN PERSEPSI PELANGGAN DI KOTA BANDUNG
}

\author{
Boy Syahputra \\ Prodi Administrasi Bisnis, Fakultas Komunikasi dan Bisnis, \\ Universitas Telkom \\ email: syahputra79@gmail.com
}

\section{ABSTRAK}

Tujuan dari penelitian itu untuk menyusun peta posisi (positioning map) dari perusahaan jasa travel Bandung-Jakarta pp berdasarkan persepsi pelanggan. Top brand perusahaan jasa travel Bandung-Jakarta pp adalah Cipaganti, X-Trans, Citi-Trans, Day-Trans, dan Baraya. Metode penelitian yang digunakan adalah metode kuantitatif dengan analisis deskriptif menggunakan multidimensi scaling dalam menentukan positioning map antar perusahaan jasa travel BandungJakarta pp yang meliputi delapan atribut (tarif, kualitas pelayanan, lokasi pool, lokasi tujuan, ketepatan waktu, kenyamanan, variasi jadwal keberangkatan, fasilitas online) menurut persepsi pelanggan dengan jumlah responden sebanyak 500 orang. Hasil penelitian bahwa pelanggan Cipaganti adalah pesaing utama Xtrans, Xtrans adalah pesaing utama dari Cititrans, dan Cititrans adalah pesaing utama dari Daytrans, dan Daytrans adalah pesaing utama dari Baraya.

Kata kunci : positioning map, multidimensional scaling, perusahaan jasa travel 
Peningkatan kegiatan perekonomian saat ini di Indonesia, khususnya Kota Bandung sebagai salah satu kota tujuan wisata semakin mendorong mobilitas masyarakat untuk berpergian baik dalam rangka kegiatan bisnis, keperluan keluarga maupun tujuan rekreasi. Kota Bandung adalah kota yang paling banyak dikunjungi wisatawan lokal terutama dari Jakarta. Oleh karena itu, hal tersebut mendorong peningkatan perkembangan bisnis transportasi dimana salah satunya adalah bisnis travel yang nyaman, tepat waktu, ramah, dan ekonomis baik dari segi kualitas maupun kuantitas.

Sistem transportasi antar kota yang ditandai dengan dibukanya akses tol cipularang pada tahun 2005 semakin memberikan kemudahan akses dari Jakarta menuju Bandung. Sehingga jarak yang terbilang jauh dahulu sekarang sudah dapat ditempuh hanya dengan waktu 2-3 jam perjalanan, dan semakin banyak orang yang melakukan perjalanan pulang-pergi Jakarta-Bandung dalam sehari. Hal ini menjadikan jasa travel Jakarta-Bandung pp sebagai salah satu peluang usaha yang menjanjikan. Keunggulan travel itu sendiri dibandingkan dengan moda transportasi lain seperti kereta api, bis, pesawat, dll adalah waktu yang fleksibel karena travel mempunyai keberangkatan per 1 jam atau 2 jam, loket-loket pembelian tersebar di kota asal dan tujuan sehingga mudah diakses oleh konsumen, selain itu kepraktisan juga termasuk keunggulan memakai travel karena untuk memesan sebuah kursi di travel konsumen tidak harus berdesak-desakan di terminal atau stasiun. Disamping itu, tiket travel dapat dipesan melalui telepon dan konsumen pasti memiliki tempat duduk kosong.

Banyaknya perusahaan jasa travel yang beroperasi untuk tujuan Jakarta-Bandung saat ini, semakin memberikan pilihan bagi pengguna jasa travel, khususnya pengguna yang sering pulang-pergi Jakarta-Bandung pp. Akan tetapi bagi para perusahaan jasa travel dengan semakin banyaknya pemain dalam bisnis jasa travel, fenomena ini menjadikan suatu tantangan bagi usaha mereka. Tantangan ini juga semakin bertambah semenjak diakhir tahun 2008 pemerintah menaikan harga bahan bakar sehingga bisnis travel harus merubah strategi bersaing mereka salah satunya adalah dengan perubahan tarif. Mereka harus terus memikirkan strategi untuk terus bertahan di industri ini, disebabkan semakin ketatnya persaingan. Mereka harus terus memikirkan bagaimana cara menarik konsumen agar konsumen dapat melakukan keputusan pembelian tiket terhadap travelnya masing-masing. Pemain utama dalam bisnis jasa travel Jakarta-Bandung pp itu sendiri antara lain Cipaganti, X-Trans, Day Trans, Baraya, dan Citi Trans.

Saat ini persaingan bisnis jasa travel semakin kompetitif, maka aspek positioning produk merupakan suatu hal yang penting. Keberhasilan suatu produk dalam suatu persaingan tergantung pula dari bagaimana suatu produk tersebut diposisikan pada pasar sasaran yang dituju dan bagaimana konsumen mempersepsikan produk yang ditawarkan tersebut sebagaimana dinyatakan oleh Kotler\&Keller (2009:293). Mengetahui positioning suatu perusahaan berdasarkan persepsi konsumen merupakan hal penting. Keberhasilan positioning sangat tergantung pada persepsi konsumen tentang perusahaan tersebut. Ketika perusahaan mendefinisikan persaingan, perusahaan harus menentukan bagaimana persepsi konsumen terhadap persaingan dan harus memikirkan atribut apa saja yang dinilai penting oleh konsumen ketika konsumen mengevaluasi produk (Belch, 2008:65). Untuk dapat mengetahui positioningdari perusahaan jasa travel di kota Bandung untuk tujuan Bandung - Jakarta pp, maka perlu dilakukan riset positioning berdasarkan persepsi pelanggan di kota Bandung melalui peta persepsi pelanggannya.

Berdasarkan paparan yang telah dijelaskan sebelumnya, maka peneliti tertarik untuk melakukan penelitian terhadap lima pemain utama dalam bisnis jasa travel di Bandung yaitu, Cipaganti, X-Trans, Day Trans, Baraya,dan Citi Trans. Karena kelima merek tersebut merupakan top brand Bandung-Jakarta travel service companies yang 


\section{JURNAL}

MANAJEMEN

INDONESIA

Vol. 14. No. 2

Agustus 2014 sekaligus memiliki pool terbanyak dibandingkan perusahaan jasa travel sejenis lainnya. Maka penelitian ini berusaha untuk menganalisis positioning kelimaperusahaan jasa travel tersebut berdasarkan persepsi konsumen.

\section{Kajian Pustaka}

Teori positioning didasarkan pada tiga proposisi (Ries \& Trout, 2000). Pertama, kita hidup berdasarkan komunikasi dari masyarakat dan diserang dengan banyak informasi setiap hari. Kedua, pikiran telah mengembangkan sistem pertahanan terhadap kekacauan informasi. Ketiga, satu-satunya cara untuk mengantisipasi kekacauan adalah melalui pesan yang di sederhanakan dan terfokus untuk menerima informasi. Lebih jauh lagi, Ries dan Trout (2000) mengatakan bahwa persaingan dalam pemasaran bukan di dalam dunia nyata tetapi ada di dalam benak atau pikiran konsumen.

Menurut Kotler \& Keller (2009:225), positioning adalah pengaturan produk untuk menduduki tempat yang jelas, berbeda, dan diinginkan dibandingkan produk pesaing dalam pikiran konsumen sasaran. Sementara itu, Urban \& Hauser (1993) menyatakan bahwa positioning sangat penting untuk produk baru. Tidak hanya harus produk baru dapat memberikan manfaat kebutuhan pelanggan, tetapi harus melakukannya lebih baik dari kompetitor.

Belch (2008:65) mengemukakan ada enam langkah yang harus dilakukan dalam menentukan positioning, yaitu: identifikasi para pesaing, riset persepsi konsumen, menentukan posisi pesaing berdasarkan atribut, dan membandingkan antara pesaing satu dengan yang lain. Untuk melakukan hal ini perlu mengadakan riset konsumen yang meliputi kegiatan: menganalisis preferensi konsumen, mengetahui posisi yang dikehendaki oleh konsumen terhadap suatu produk, dan membuat keputusan positioning, dan memantau posisi.

Kotler \& Keller (2009:213) menyatakan bahwa perilaku konsumen merupakan studi tentang cara individu, kelompok, dan organisasi menyeleksi, membeli, menggunakan, dan memposisikan barang, jasa, gagasan atau pengalaman untuk memuaskan kebutuhan dan keinginan mereka. Pendapat tersebut senada Sciffman dan Kanuk (2007:5) dan Hawkins dan Mothersbaugh (2010:6).

Bigné et al (2002:87) menyatakan bahwa terdapat beberapa atribut yang mempengaruhi konsumen dalam bisnis jasa travel yaitu: leading sector company with long standing experience, offers good value for money, good relationship with an employee, recommendation from friend or relation, service proved satisfactory in the past, inspire confidence, easily accessible, have been using for years now, customer totally involved with agency, saving time for looking up other agencies, has wide ranging offers, the service to be efficient, always on schedule, offers customer cards, offers complementary services, dan send catalog for customers.

Silva et al (2002:1327) menyatakan bahwa terdapat beberapa atribut yang mempengaruhi konsumen dalam bisnis jasa travel yaitu: cost, work quality, delivery time, responsiveness, innovative ability, dan good design ideas.

Shahin et al (2011:176) menyatakan bahwa terdapat beberapa atribut yang mempengaruhi konsumen dalam bisnis jasa travel yaitu: external appearance of the building, modern tools and equipments, appearance of the personnel, appropriate equipments used to deliver service, delivering service at the designated time, willingness to solve customers' problems, delivering on-time and just-in-time service, delivering service exactly at the promised time, accuracy of recording customers' information, informing customers quickly, quick service delivery, willingness to help customers, enough time to respond to customers, good behaviour of personnel, safety and security of agency and services, courtesy and good speaking of the personnel, enough knowledge of the personnel, individual attention to customers, appropriate time table for service delivery, delivering specialized service to customers, friendliness of service delivery personnel, and understanding special needs of customers. 
Yusta et al (2011:77) menyatakan bahwa terdapat beberapa atribut yang mempengaruhi konsumen dalam bisnis jasa travel yaitu: information assymetries, trust, perceived risk, dan transaction cost. Lebih jauh lagi, Purnama et al (2011:12) menyatakan bahwa terdapat beberapa atribut yang mempengaruhi konsumen dalam bisnis jasa travel yaitu: harga tiket yang sesuai pelayanan, harga tiket yang kompetitif, banyaknya agen resmi, kerjasama penyediaan paket wisata dengan agen resmi, kemudahan pembelian tiket, SDM yang tangguh, petugas yang responsive, kecepatan penanganan keluhan, pemberian informasi yang jelas dan akurat, ketepatan waktu, kepercayaan penumpang, empati petugas, keramahan petugas, kebersihan kendaraan, fasilitas kendaraan, perhatian terhadap keinginan penumpang.

Azizah et al (2009:17) menyatakan bahwa terdapat beberapa atribut yang mempengaruhi konsumen dalam bisnis jasa travel yaitu: kebutuhan akan jasa transportasi, kenyamanan, penyediaan minuman untuk penumpang, kepuasan terhadap pelayanan, rasa aman, perlindungan asuransi, keamanan barang, pelayanan yang ramah, komunikasi yang baik, perhatian pada keperluan penumpang, fasilitas mobil yang lengkap, interior dan eksterior mobil, ketepatan keberangkatan, respon terhadap masalah, kelayakan mobil, lokasi, sopir berpengalaman, harga tiker murah, kondisi supir, dan kebersihan kendaraan.

Istiqarah et al (2009:36) menyatakan bahwa terdapat beberapa atribut yang mempengaruhi konsumen dalam bisnis jasa travel yaitu:pelayanan, harga tiket, kenyamanan, keamanan barang, dan fasilitas kendaraan. Warman et al (2014:25) menyatakan bahwa terdapat beberapa atribut yang mempengaruhi konsumen dalam bisnis jasa travel yaitu:jaminan keselamatan, kenyamanan, tempat menunggu kendaraan, sarana pendukung operasional, rute yang terjadwal dengan baik, waktu tempuh, dan kecepatan.

Berdasarkan penelitian pendahuluan dan penelitian sebelumnya diperoleh delapan atribut yang menjadi pertimbangankonsumen dalam memutuskan untuk menggunakan jasa travel yaitu: tarif, pelayanan, lokasi, tempat tujuan, ketepatan waktu, kenyamanan, jadwal keberangkatan, dan kepraktisan.

Tarif adalah biaya atau harga yang harus dibayar oleh konsumen yang menggunakan jasa travel tersebut. Pentingnya atributtarif sebagaimana yang dinyatakan dalam penelitian yang dilakukan oleh Bigné et al (2002), Silva et al (2002), Yusta dan Ruiz (2011), Verina et al (2014), Purnama dan Raditya (2011), Azizah dan Ali (2009), Istiqarah (2009), Getricya dan Jatikusuma (2012), Andini (2012), Sari (2012), Rahayuningsih (2008).

Pelayanan adalah kualitas produk (jasa) pelayanan yang diterima oleh konsumen yang menggunakan jasa travel tersebut. Pentingnya atribut kualitas produk (jasa) juga dinyatakan dalam penelitian yang dilakukan oleh Bigné et al (2002), Silva et al (2002), Shanin dan Nekuie (2011), Verina et al (2014), Azizah dan Ali (2009), Istiqarah (2009), Nurcahyana (2010), Getricya dan Jatikusuma (2012), Andini (2012), Sari (2012), Rahayuningsih (2008).

Lokasi adalah tempat atau saluran distribusi pelayanan jasa travel. Sedangkan tempat tujuan adalah banyaknya rute tujuan dari saluran distribusi pelayanan jasa travel. Pentingnya atribut lokasi dan tempat tujuan juga dinyatakan dalam penelitian yang dilakukan oleh Shanin dan Nekuie (2011), Purnama dan Raditya (2011), Azizah dan Ali (2009), Warman et al(2014), Sari (2012).

Ketepatan waktu adalah ketepatan waktu pelayanan jasa travel. Pentingnya atribut ketepatan waktu juga dinyatakan dalam penelitian yang dilakukan oleh Bigné et al (2002), Silva et al (2002), Shanin dan Nekuie (2011), Purnama dan Raditya (2011), Azizah dan Ali (2009).

Kenyamanan adalah kondisi lingkungan yang menyebabkan penumpang merasa nyaman dalam menggunakan fasilitas pelayanan jasa travel. Pentingnya atribut kenyamanan juga dinyatakan dalam penelitian yang dilakukan oleh Warman et al(2014), 
Istiqarah (2009), Azizah dan Ali (2009).

\section{JURNAL \\ MANAJEMEN \\ INDONESIA}

Vol. 14. No. 2

Agustus 2014
Jadwal keberangkatan adalah jadwal atau skedul pemberangkatan penumpang jasa travel. Pentingnya atribut jadwal keberangkatan juga dinyatakan dalam penelitian yang dilakukan oleh Bigné et al (2002), Silva et al (2002), Shanin dan Nekuie (2011), Warman et al (2014). Kepraktisan adalah kemudahan akses konsumen dalam menggunakan jasa travel. Pentingnya atribut kepraktisan juga dinyatakan dalam penelitian yang dilakukan oleh Bigné et al (2002), Purnama dan Raditya (2011), Mujiyana dan Elissa (2013).

Menurut Solomon (2006:36), persepsi adalah proses bagaimana stimuli dipilih, diorganisasi, dan diinterpretasikan. Sensasi (sensation) mengacu pada tangapan langsung dari reseptor sensorik terhadap stimuli yang ditangkap oleh manusia. Setelah muncul suatu sensasi maka selanjutnya akan terjadi proses exposure. Exposure adalah suatu proses sejauh mana seseorang melihat stimulus yang berada dalam jangkauan reseptor sensorik. Setelah proses exposure terjadi, maka munculah suatu attention terhadap stimuli. Attention adalah proses sejauh mana manusia dapat fokus terhadap stimuli dalam jangkauan exposure mereka. Kemudian setelah terjadi suatu attention, selanjutnya akan terjadi proses interpretation. Interpretation mengacu pada proses dimana manusia memberikan suatu arti terhadap rangsangan sensorik. Setelah proses interpretation selanjutnya akan terjadi suatu response terhadap stimuli yang diberikan. Setelah manusia merespon stimuli, maka selanjutnya terjadilah suatu persepsi (perception).

Dasar dalam pembuatan kerangka pemikiran dalam penelitian ini adalah model yang dikemukakan oleh Solomon (2006:237) yang dimodifikasi.



Gambar 1.Kerangka Pemikiran

Sumber: Modifikasi dari Solomon (2006:36)

\section{Metode Penelitian}

Berdasarkan tujuan utama dalam penelitian ini adalah untuk menggambarkan suatu positioning map perusahaan jasa travel Bandung - Jakarta pp berdasarkan persepsi konsumen di Kota Bandung, maka penelitian ini termasuk jenis penelitian deskriptif dan menggunakan metode kuantitatif.

Menurut Sekaran (2006:158), penelitian deskriptif adalah penelitian yang dilakukan untuk mengetahui dan dapat untuk menjelaskan karakteristik variabel yang diteliti dalam suatu situasi.

Metode penelitian kuantitatif dapat diartikan sebagai metode penelitian yang berlandaskan pada filsafat positivisme, digunakan untuk meneliti pada populasi atau sampel tertentu, teknik pengambilan sampel pada umumnya dilakukan secara random, pengumpulan data menggunakan instrumen penelitian, analisis data bersifat kuantitatif/statistik dengan tujuan untuk menguji hipotesis yang telah ditetapkan (Sugiyono, 2013:13). 
Simamora (2005:234) menyatakan sebagai teknik multivariat dalam golongan interdependenced technique, multidimensional scaling (MDS) adalah salah satu prosedur yang digunakan untuk memetakan persepsi dan preferensi para responden secara visual dalam peta geometri. Menurut Simamora (2005:238), ada beberapa isu yang perlu diperhatikan oleh peneliti sebelum melakukan MDS, antara lain:

Identifikasi objek relevan. Peneliti perlu memeriksa objek-objek yang relevan. Objek-objek yang tidak relevan akan mengganggu peta persepsi serta mempersulit interpretasi dimensi-dimensi perseptual diantara objek-objek yang diuji.

Batasan merek relevan bersifat subjektif. Untuk memperolehnya dapat dilakukan riset pendahuluan, bisa pula berdasarkan data sekunder berupa data yang dipakai oleh pihak lain.

Similarity versus preference. Setelah objek ditentukan, perlu ditentukan juga berdasarkan pada apa persepsi terhadap objek-objek tersebut dipetakan, pada kesamaan (similarity) ataukah preferensi (preference). Kedua jenis input data akan menghasilkan persepsi yang berbeda. Dengan kesamaan dimana dimensi-dimensi objek dapat digali, tetapi determinasi pilihan tidak terungkap, sedangkan dengan preferensi dimana pilihan dapat terefleksi, namun sulit membandingkan kesamaan antara satu objek dan objek lain sebab dimensi yang dipakai untuk membangun preferensi bisa saja berbeda untuk objek yang berbeda.

Desain riset. Perlu ditentukan apakah dalam MDS akan menggunakan desain decompotional (attribute-free) ataukan compotional (attribute-based). Dengan desain decompotional hanya akan mengukur kesan umum (general impression), sedangkan metode compotional digunakan untuk mengukur kesan atas sejumlah merek berdasarkan sekumpulan atribut.

Kesamaan diukur dengan membandingkan data setiap objek, umumnya dengan cara melakukan korelasi antar objek. Kesamaan turunan (derived similarity) kemudian diolah dengan analisis faktor ataupun analisis diskriminan untuk mengidentifikasi dimensi-dimensi yang dipakai responden dalam membedakan objek-objek tersebut.

Menurut Simamora (2005:236), MDS dapat digunakan dalam berbagai aplikasi pemasaran seperti: Pengukuran citra. Kalau peta persepsi setiap individu kita ukur, lalu kita lakukan perbandingan antar-individu, objek-objek yang menempati posisi yang relatif sama pada sebagian besar atau semua individu, tentu sudah memiliki citra yang kuat.

Segmentasi pasar. Merek dan konsumen dapat diposisikan dalam peta yang sama, kemudian kelompok-kelompok konsumen dengan persepsi yang relatif homogen dapat diidentifikasi.

Pengembangan produk baru. Melalui spatial map dapat dilihat area-area yang masih kosong atau yang pemainnya belum ada. MDS dapat dipakai untuk mengevaluasi konsep-konsep produk baru dan merek-merek saat ini untuk bagaimana konsumen mempersepsikan konsep-konsep produk tersebut. Proporsi preferensi untuk setiap produk baru adalah sebuah indikator untuk mengetahui kesuksesannya.

Menilai efektivitas iklan. Kalau iklan ditujukan untuk membentuk brand position, MDS dapat dipakai untuk mengukur apakah posisi yang diinginkan sudah tercapai. Dengan kata lain, apakah iklan efektif dalam membentuk brand position.

Analisis harga. Kita dapat membuat spatial map dengan dan tanpa memasukkan faktor harga. Kemudian bandingkan kedua spatialmap. Perbedaan diantara keduanya mencerminkan dampak harga terhadap persepsi konsumen.

Kepuasan saluran. Kalau melakukan judgement tentang kompatibilitas atas sejumlah merek dengan outlet yang berbeda-beda, informasi dari spatial map yang terkait saluran distribusi tersebut dapat dipakai bahan pertimbangan.

Menurut Churcill dan Iacobucci (2005:603), MDS adalah sebuah teknik untuk mengukur dan mewakili persepsi orang tentang berbagai objek produk, merek, toko, dan lain-lain.Terdapat beberapa faktor kunci yang harus diperhatikan ketika 


\section{JURNAL \\ MANAJEMEN \\ INDONESIA}

Vol. 14. No. 2

Agustus 2014 akan melakukan analisis MDS, yaitu: tentukan merek atau produk yang akan digunakan, tentukan bagaimana penilaian tentang kesamaan dapat terkandung dan membentuk stimuli, memutuskan bagaimana penilaian akan dirangkum, kumpulkan dan analisis penilaian untuk menghasilkan peta persepsi, dan memberikan nama pada dimensi yang telah dihasilkan.Peta geometri yang disebut spatial map atau perceptual map merupakan penjabaran berbagai dimensi yang berhubungan. Merek-merek yang memiliki kesamaan tinggi menempati posisi berdekatan (Konuk dan Altuna, 2011). Merek-merek yang berbeda menempati posisi berjauhan. Jadi, dari peta persepsi tersebut akan dapat dilihat mana merek-merek yang bersaing dekat dan mana yang jauh.

Menurut Aaker, Kumar dan Day (2007:592), multidimensional scaling adalah teknik untuk menggambarkan masalah umum posisi objek dalam ruang persepsi.Sedangkan menurut Sekaran (2006:303), MDS adalah analisis yang memberikan gambaran spasial persepsi responden mengenai produk, layanan, atau unsur penelitian lainnya, dan menyoroti persamaan dan perbedaan yang dirasakan.

Berdasarkan isu-isu diatas, agar dapat memberi gambaran yang jelas mengenai deskripsi peta persepsi (perceptual map) maka digunakan pendekatan perceptual map yang dikutip dari Aaker, Kumar dan Day (2007:593).

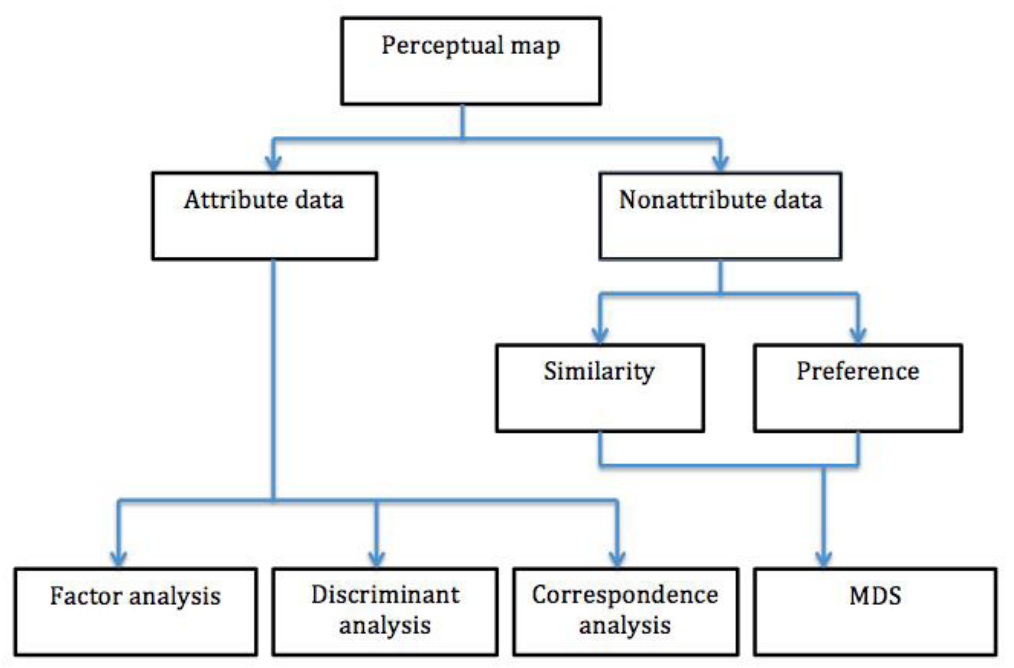
Gambar 2. Pendekatan membuat Perceptual Map
Sumber : Aaker, Kumar, Day (2007:593)

Variabel penelitian adalah suatu atribut atau sifat atau nilai dari orang, objek, atau kegiatan yang mempunyai variasi tertentu yang ditetapkan oleh peneliti untuk dipelajari dan ditarik kesimpulannya(Sugiyono, 2013:59). Atribut yang diambil berdasarkan dari beberapa penelitian terdahulu, bentuk variabel dan operasionalnya akan ditampilkan sebagai berikut :

Tabel 1. Variabel Operasional

\begin{tabular}{|c|c|c|c|}
\hline Variabel & Konsep Variabel & Indikator & Skala \\
\hline Tarif & Kemenarikan tarif yang ditawarkan & Daya tarik tarif & Ordinal \\
\hline $\begin{array}{c}\text { Kualitas } \\
\text { Pelayanan } \\
\end{array}$ & Kualitas pelayanan yang diberikan & Pelayanan yang diberikan & Ordinal \\
\hline $\begin{array}{c}\text { Lokasi } \\
\text { pemberangkatan }\end{array}$ & $\begin{array}{c}\text { Kemudahan mengakses pool } \\
\text { pemberangkatan }\end{array}$ & $\begin{array}{c}\text { Tingkat kemudahan akses pool } \\
\text { pemberangkatan }\end{array}$ & Ordinal \\
\hline Lokasi tujuan & Kestrategisan lokasi tujuan & $\begin{array}{c}\text { Tingkat kestrategisan lokasi } \\
\text { tujuan }\end{array}$ & Ordinal \\
\hline $\begin{array}{l}\text { Ketetapan } \\
\text { waktu }\end{array}$ & Ketepatan waktu pemberangkatan & $\begin{array}{l}\text { Tingkat ketepatan waktu } \\
\text { pemberangkatan }\end{array}$ & Ordinal \\
\hline Kenyamanan & $\begin{array}{l}\text { Kondisi kenyamanan yang dirasakan } \\
\text { pelanggan atas fasilitas }\end{array}$ & $\begin{array}{c}\text { Tingkat kenyamanan yang } \\
\text { dirasakan pelanggan atas } \\
\text { fasilitas }\end{array}$ & Ordinal \\
\hline $\begin{array}{c}\text { Variasi jadwal } \\
\text { pemberangkatan }\end{array}$ & $\begin{array}{c}\text { Keragaman jadwal pemberangkatan } \\
\text { yang fleksibel }\end{array}$ & $\begin{array}{l}\text { Tingkat keragaman jadwal } \\
\text { pemberangkatan }\end{array}$ & Ordinal \\
\hline Fasilitas online & Ketersediaan fasilitas online & $\begin{array}{c}\text { Fasilitas online yang diberikan } \\
\text { (wi-fi, online booking system, } \\
\text { website) }\end{array}$ & Ordinal \\
\hline
\end{tabular}


Untuk mendapatkan peta positioning perusahaan jasa travel Bandung-Jakarta $\mathrm{pp}$, data yang diperoleh dari responden akan diolah terlebih dahulu menggunakan metode multidimensional scaling dalam aplikasi SPSS versi 21. Dengan metode ini positioning beberapa perusahaan jasa travel Bandung-Jakarta pp berdasarkan persepsi pelanggan dapat digambarkan dalam suatu peta perseptual. Peta perseptual tersebut akan memberikan gambaran bagaimana pelanggan mempersepsikan lima perusahaan jasa travel Bandung-Jakarta pp yang diteliti berdasarkan tingkat kesamaan antar merek, serta mengenai preferensi konsumen terhadap lima perusahaan jasa travel Bandung-Jakarta pp tersebut berdasarkan atribut terpilih. Tingkat persaingan tiap perusahaan jasa travel Bandung-Jakarta pp dapat diketahui dengan cara menghitung euclidean distance antara pool location satu dengan yang lainnya. Prinsipnya semakin dekat euclidean distance, maka semakin tinggi tingkat persaingannya. Analisis terhadap atribut dilakukan dengan cara menghitung euclidean distance posisi tiap perusahaan jasa travel Bandung-Jakarta pp terhadap atribut yang berkaitan. Prinsipnya semakin dekat euclidean distance coffee shop terhadap atribut yang berkaitan, maka semakin baik perusahaan jasa travel Bandung-Jakarta pp berdasarkan atribut tersebut.

Positioning map antar perusahaan jasa travel Bandung-Jakarta pp yang meliputi delapan atribut yaitu: (a) tarif, (b) kualitas pelayanan, (c) lokasi pool, (d) lokasi tujuan, (e) ketepatan waktu, (f) kenyamanan, (g) variasi jadwal keberangkatan, dan (h) fasilitas online yang didasarkan pada persepsi pelanggan dengan jumlah responden sebanyak 500 orang.

Ada beberapa tahapan penelitian yang dilakukan peneliti terhadap data dalam penelitian ini yaitu sebagai berikut :

1. Menentukan pemain dalam bisnis jasa travel Bandung-Jakarta pp yaitu Cipaganti, X-Trans, Day Trans, Baraya,dan Citi Trans.

2. Menentukan atribut utama yang dimiliki perusahaan jasa travel Bandung-Jakarta pp.

3. Mengumpulkan informasi dari responden

4. Pemetaan persepsi responden

5. Menentukan area preferensi konsumen dalam pemetaan persepsi

6. Menginterpretasikan data

7. Kesimpulan

Tahapan pengolahan data menggunakan SPSS dilakukan dengan sebagai berikut:

1. Input data anda ke dalam worksheet SPSS (membuat matriks data mentah)

2. Untuk menghitung menghitung stress measure dan RSQ dilakukan dengan memilih pada menu Analyze - Scale - Multidimensional Scalling. Setelah muncul kotak dialog Multidimensional Scaling, masukkan semua variabel ke dalam kotak variables, pada Shape, pilih Rctangular, kemudian klik Model disamping kanan atas.

3. Untuk menghitung koordinat dilakukan dengan menugngu hingga munculnya kotak dialog Multidimensional Scaling - Model, maka kita dapat memilih pada Level of Measurement Interval (sesuai jenis data), dan pada Conditionality adalah Row agar perbandingan dilakukan antar row/kolom saja, kemudian klik Continue.

4. Untuk menghitung jarak antar objek (euclidean distance), setelah keluar ke kotak dialog pertama, klik Option, lalu centang Group Plots, kemudian klik OK. Dari output kita dapatkan kedekatan masing-masing atribut pada masing-masing baris (row) terhadap masing-masing merk travel Bandung Jakarta pp berdasarkan persepsi konsumen dalam sebuah pemetaan perseptual dua dimensi.

Jika dalam perceptual map tidak terlihat dengan jelas perbedaan letak secara visual, maka untuk mengatasi masalah tersebut dapat dengan menghitung jarak euclidean masing-masing merek. Prinsipnya, semakin kecil jarak euclidean, semakin dekat jarak setiap objek, dan semakin tinggi pula tingkat persaingannya. 
Untuk menghitung jarak euclidean, perlu untuk diketahui koordinat setiap objek ter-

JURNAL

MANAJEMEN

INDONESIA

Vol. 14. No. 2

Agustus 2014 lebih dahulu. Kemudian jarak euclidean dapat dihitung dengan rumus :

$$
\left.D=\sqrt{\left(\mathrm{x}_{i}\right.}-\mathrm{x}_{\mathrm{i}-1}\right)^{2}+\left(\mathrm{y}_{\left.\mathrm{i}-\mathrm{y}_{\mathrm{i}-1}\right)^{2}}\right.
$$

Dimana :

$$
\begin{aligned}
& \mathrm{D}=\text { Jarak geometris (jarak euclidean) } \\
& \mathrm{xi}=\text { Koordinat } \mathrm{x} \text { ke- } \mathrm{i} \\
& \mathrm{yi}=\text { Koordinat } \mathrm{y} \text { ke- } \mathrm{i}
\end{aligned}
$$

Dari dua bobot relatif dimensi ( $\mathrm{x}$ dan $\mathrm{y}$ ) yang diketahui dapat digambarkan vektor arah untuk semua atribut produk-produk yang dibandingkan dalam posisinya. Arah vektor tiap atribut tersebut menunjukkan akan semakin baik atau semakin disukai konsumen. Selanjutnya untuk mengetahui urutan rangking produk-produk yang dibandingkan berdasarkan tiap atribut maka dapat dilakukan dengan menarik garis tegak lurus terhadap vektor tersebut dan urutan rangking produk dapat diurutkan dari produk yang paling dekat dengan ujung vektor (panah) atribut tersebut.

RSQ dalam multidimensional scaling mengindikasikan proporsi varians data input yang dapat dijelaskan oleh model MDS. Semakin tinggi RSQ, semakin baik model MDS. Menurut Maholtra dalam buku Simamora (2005:268), model multidimensional scaling dapat diterima bila RSQ $\geq 0,6$.

Dalam multidimensional scaling tingkat stress mengindikasikan proporsi varians perbedaan (disparity) yang tidak dijelaskan oleh model. Dalam buku Simamora (2005:268-269), Maholtra merumuskan rumus yang paling banyak digunakan pada MDS yaitu rumus Kruskal Tipe 1 :

$$
\text { Stress }=\sqrt{\mid \frac{\sum\left(d_{i j}-\hat{d}_{i j}\right)^{2}}{\sum\left(d_{i j}-\bar{d}\right)^{2}}}
$$



Untuk interpretasi berlaku prinsip "Semakin rendah stress, semakin baik model MDS yang dihasilkan". Untuk mengetahui indikator batasan nilai stress sebagaimana dikutip dari Maholtra dalam buku Simamora (2005:269) yaitu sebagai berikut :

Tabel 2. Kategori Penilaian Kelayakan Model Berdasarkan S-Stress

\begin{tabular}{|c|c|}
\hline Stress (Percent) & Goodness of Fit \\
\hline 20 & Poor \\
\hline 10 & Fair \\
\hline 5 & Good \\
\hline 2,5 & Excellent \\
\hline 0 & Perfect \\
\hline
\end{tabular}

Sumber: Simamora (2005:269) 


\section{Pembahasan}

Dari segi persepsi pelanggan berdasarkan euclidean distance-nya menunjukkan angka yang terkecil,maka Cipaganti adalah pesaing utama Xtrans, Xtrans adalah pesaing utama dari Cititrans, dan Cititrans adalah pesaing utama dari Daytrans, dan Daytrans adalah pesaing utama dari Baraya.

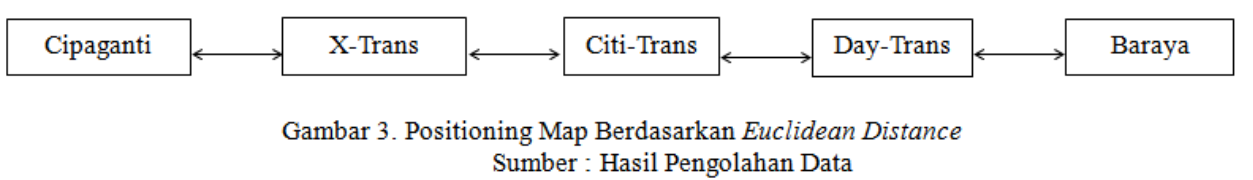

\section{JURNAL \\ MANAJEMEN \\ INDONESIA}

Vol. 14. No. 2

Agustus 2014

Peta positioning perusahaan jasa travel Bandung-Jakarta pp berdasarkan masing-masing atribut yaitu (a) tarif, (b) kualitas pelayanan, (c) lokasi pool, (d) lokasi tujuan, (e) ketepatan waktu, (f) kenyamanan, (g) variasi jadwal keberangkatan, dan (h) fasilitas online.

Dilihat dari atribut tarifberdasarkan persepsi pelanggan terhadap perusahaan jasa travel Bandung-Jakarta pp,Baraya menduduki peringkat pertama, peringkat kedua ditempati oleh Xtrans, peringkat ketiga ditempati oleh Daytrans, peringkat keempat ditempati oleh Cititrans, dan peringkat kelima ditempati oleh Cipaganti.

Dilihat dari atribut kualitas pelayanan berdasarkan persepsi pelanggan terhadapperusahaan jasa travel Bandung-Jakarta pp, Cipaganti menduduki peringkat pertama, peringkat kedua ditempati oleh Cititrans, peringkat ketiga ditempati oleh Daytrans, peringkat keempat ditempati oleh Xtrans, dan peringkat kelima ditempati oleh Baraya.

Dilihat dari atribut lokasi pool berdasarkan persepsi pelanggan terhadap perusahaan jasa travel Bandung-Jakarta pp, Baraya menduduki peringkat pertama, peringkat kedua ditempati oleh Xtrans,peringkat ketiga ditempati oleh Cipaganti, peringkat keempat ditempati oleh Cititrans, dan peringkat kelima ditempati oleh Daytrans.

Dilihat dari atribut lokasi tujuan berdasarkan persepsi pelanggan terhadapperusahaan jasa travel Bandung-Jakarta pp, Xtrans menduduki peringkat pertama,peringkat kedua ditempati oleh Cipaganti,peringkat ketiga ditempati oleh Baraya, peringkat keempat ditempati oleh Cititrans, dan peringkat kelima ditempati oleh Daytrans.

Dilihat dari atribut ketepatan waktu berdasarkan persepsi pelanggan terhadap perusahaan jasa travel Bandung-Jakarta $\mathrm{pp}$,Xtrans menduduki peringkat pertama, peringkat kedua ditempati oleh Cipaganti, peringkat ketiga ditempati oleh Cititrans, peringkat keempat ditempati oleh Daytrans, dan peringkat kelima ditempati oleh Baraya.

Dilihat dari atribut kenyamanan berdasarkan persepsi pelanggan terhadap perusahaan jasa travel Bandung-Jakarta pp, Cititrans menduduki peringkat pertama, peringkat kedua ditempati oleh Cipaganti,peringkat ketiga ditempati oleh Daytrans, dan peringkat keempat ditempati oleh Xtrans, dan peringkat kelima ditempati oleh Baraya.

Dilihat dari atribut fasilitas online berdasarkan persepsi pelanggan terhadapperusahaan jasa travel Bandung-Jakarta pp, Cipaganti menduduki peringkat pertama, peringkat kedua ditempati oleh Daytrans,peringkat ketiga ditempati oleh Xtrans, peringkat keempat ditempati oleh Cititrans, dan peringkat kelima ditempati oleh Baraya.

\section{Kesimpulan}

Hasil penelitian bahwa pelanggan Cipaganti adalah pesaing utama Xtrans, Xtrans adalah pesaing utama dari Cititrans, dan Cititrans adalah pesaing utama dari Daytrans, dan Daytrans adalah pesaing utama dari Baraya.

Berdasarkan delapan atribut tersebut, pelanggan perusahaan jasa travel Bandung-Jakarta pp menyatakan bahwa Baraya perusahaan jasa travel Bandung-Jakarta pp terbaik berdasarkan atribut tarif dan yang terburuk adalah Cipaganti. Cipaganti adalah perusahaan jasa travel Bandung-Jakarta pp terbaik berdasarkan atribut kualitas pelayanan, dan yang terburuk adalah Baraya. Baraya adalah perusahaan jasa travel Bandung-Ja- 
karta pp terbaik berdasarkan atribut lokasi pool dan yang terburuk adalah Daytrans.

Xtrans adalah perusahaan jasa travel Bandung-Jakarta pp terbaik berdasarkan

JURNAL

MANAJEMEN

INDONESIA

Vol. 14. No. 2

Agustus 2014 atribut lokasi tujuan dan yang terburuk adalah Daytrans. Xtrans adalah perusahaan jasa travel Bandung-Jakarta pp yang terbaik untuk atribut ketepatan waktu dan yang terburuk adalah Baraya. Cititrans adalah perusahaan jasa travel Bandung-Jakarta pp terbaik berdasarkan atribut kenyamanan dan yang terburuk adalah Baraya. Xtrans adalah perusahaan jasa travel Bandung-Jakarta pp terbaik berdasarkan atribut variasi jadwal keberangkatan dan yang terburuk adalah Daytrans. Cipaganti termasuk perusahaan jasa travel Bandung-Jakarta pp yang terbaik untuk atribut fasilitas online dan yang terburuk adalah Baraya.

\section{Daftar Pustaka}

Andini, Prisca. (2012). Analisis Faktor-Faktor yang Mempengaruhi Keputusan Pembelian Mobil Hyundai i2.Skripsi FEB UNDIP Semarang.

Azizah dan Hapzi Ali.(2009). Analisis Faktor-Faktor Yang Mempengaruhi Motivasi Konsumen dalam Memutuskan Pembelian Jasa PO.Imi Fatma Sakti Travel Jambi.Jurnal Ilmiah Universitas Batanghari, Jambi.

Belch, George. (2008). Advertising \& Promotion: An Integrated Marketing Communication Perspective. New York: McGraw Hill

Bigné, J. Enrique.,et al. (2002). The concept mapping approach in marketing: anapplication in the travel agencies sector. Qualitative Market Research: An International Journal, Vol. 5 Iss 2 pp. 87 - 95.

Churcill, G.A., and Iacobucci, D. (2005). Marketing Research: Methodological Foundation. Belmont: Thompson-South Western.

Getricya, Wanda dan Edin S. Jatikusuma.(2012). Analisis Faktor-Faktor yang Mempengaruhi Keputusan Pembelian Konsumen pada Produk Minuman Berisotonik Pocari Sweat.Skripsi STIE MDP.

Hawkins\&Mothersbaugh. (2010). Consumer Behavior Building Marketing Strategy. New York: McGraw Hill

Istiqarah, Choirum Indah. (2009). Repositioning Atribut Jasa Berdasarkan Persepsi Konsumen (Studi pada Industri Jasa Travel di Kota Madiun.Jurnal Sosial, Vol. 10 Nomor 2.

Kotler, Philip., and Keller, Lane K. (2009). Manajemen Pemasaran. Terjemahan Benyamin Molan. Jakarta: Erlangga.

Mayfield, A. 2008. What is Social Media? [Online]. Tersedia pada: http://www.icrossing.co.uk/fileadmin/uploads/eBooks/What_is_Social_Media_iCrossing_ebook.pdf [Diakses 17 Agustus 2010] Aaker, Kumar, Day. (2007). Marketing Research. New York: John Wiley \& Sons.

Michaelidou, N., Siamagka, N.T., dan Christodoulides, G. 2011. Usage, Barriers and Measurement of Social Media Marketing: An Exploratory Investigation of Small and Medium B2B Brands. Industrial Marketing Management. 40 (7). 1153-1159.

Mujiyana dan Ingge Elissa. (2013). Analisis Faktor-Faktor yang Mempengaruhi Keputusan Pembelian Via Internet pada Toko Online. JurnalUndip, Vol. III No. 2

Purnama,Surya dan Rangga Raditya. (2011). Analisis Faktor-Faktor yang Menentukan Keputusan Konsumen dalam Pemilihan Penggunaan Jasa Transportasi Udara pada Maskapai Penerbangan Eva Air.Jurnal Forum Ilmiah, Vol. 8, No. 2

Ries, A., \& Trout, J. (2000). Positioning, the battle for your mind. (Rev. ed.). New York: McGraw-Hill.

Sari, Yakut Dekrita.(2012). Analisis Faktor-Faktor yang Mempengaruhi Keputusan Konsumen dalam Membeli Produk Industri Garment.Skripsi Universitas Udayana, Bali

Schiffman, Leon., and Kanuk, Lazar Leslie. (2008). Perilaku Konsumen. Jakarta: In- 
deks.

Sekaran, Uma. (2006). Research Method for Business. Jakarta: Salemba Empat.

Shahin, Arash and Nasrin Nekuie. (2011). Development of the Kano model: A novel approach based on linear logarithmic transformation with a case study in an air travel agency. Asian Journal on Quality, Vol. 12 Iss 2 pp. 176 - 188

Silva, Rui da., et al. (2002). Assessing the influence of retail buyer variables on thebuying decision-making process. European Journal of Marketing, Vol. 36 Iss 11/12 pp. $1327-1343$

Simamora, Bilson. (2005). Analisis Multivariat Pemasaran. Jakarta: Gramedia Pustaka

Solomon, Michael R. (2006). Consumer Behavior: An European Perspective. Sydney: Prentice Hall

Urban, L. G., \& Hauser, R. J. (1993). Design and marketing of new products. (2nd ed.). Englewood Cliffs, NJ: Prentice Hall.

Verina, Eunike.,et al. (2014). Faktor-faktor yang Mempengaruhi Keputusan Pembelian pada Toko Fashion di Jejaring Social Facebook.Jurnal Administrasi Bisnis, Vol.10, No.1

Warman, Andri.,et al. (2014). Karakteristik Penumpang Travel Jakarta-Bandung.Jurnal Manajemen Transportasi dan Logistik, Vol. 01 Nomor 1

Yusta, Alicia Izquierdo dan María Pilar Martínez-Ruiz. (2011). Assessing the consumer's choice of purchase channel in the tourism sector. EuroMed Journal of Business, Vol. 6 Iss 1 pp. 77 - 99

Zikmund, W.G. 2003. Business Research Methods Seven Edition. USA: South Western - Cengage Learning. 